\title{
Ogre (dans le conte merveilleux berbère)
}

Abdellah Bounfour

\section{OpenEdition}

Journals

Édition électronique

URL : https://journals.openedition.org/encyclopedieberbere/2809

DOI : 10.4000/encyclopedieberbere.2809

ISSN : 2262-7197

\section{Éditeur}

Peeters Publishers

\section{Édition imprimée}

Date de publication : 1 juin 2013

Pagination : $5721-5723$

ISBN : 978-2-7584-0184-1

ISSN : 1015-7344

\section{Référence électronique}

Abdellah Bounfour, "Ogre (dans le conte merveilleux berbère) », Encyclopédie berbère [En ligne], 35

2013, document 013, mis en ligne le 12 mars 2021, consulté le 17 février 2022. URL : http://

journals.openedition.org/encyclopedieberbere/2809; DOI : https://doi.org/10.4000/

encyclopedieberbere.2809

Ce document a été généré automatiquement le 17 février 2022.

(c) Tous droits réservés 


\title{
Ogre (dans le conte merveilleux berbère)
}

\author{
Abdellah Bounfour
}

1 Les noms berbères de l'ogre et de l'ogresse sont nombreux. E. Laoust (1949, II) en dénombre déjà une dizaine (bexxu ou croquemitaine, tamza, akukku, majjəyyul ${ }^{1}$, tteriel, tergu, agrud, ta ${ }^{\circ} z \partial n t$, tayu, zabbar...) en excluant les noms d'animaux (lion, panthère) et les personnages voisins (tagmart/asordun $n$ isəmdal, «la jument/la mule des cimetières »). Sans nier les apports de l'analyse linguistique, particulièrement l'analyse étymologique à venir, il a semblé plus sage d'étudier les caractéristiques de leur être et de leur agir ainsi que la représentation qu'on se fait d'eux à travers l'univers où ils évoluent naturellement, celui du conte merveilleux.

2 E. Laoust (1949, p. XXVI) a dressé un portrait de l'ogre et de l'ogresse comme suit :

1. L'ogre a un physique imprécis, mais il est doué d'une puissance irrésistible; il est anthropophage et préfère la chair humaine jeune, celle des enfants que son odorat détecte instantanément dès qu'elle est présente.

2. L'ogresse a un physique de "vieille femme horrible et méchante ». Elle est velue, dispose non d'une chevelure mais d'une crinière; elle a toujours des yeux 'malades', de grandes dents qui font toujours beaucoup de bruit, des «bras puissants [...] armés de griffes ». Mais, le trait physique le plus emblématique de l'ogresse ce sont ses deux immenses et lourdes mamelles qu'elle porte sur ses épaules. Elle a une voix forte; elle est rusée et, parfois, séductrice ${ }^{2}$. Comme l'ogre elle se nourrit de chair d'enfants. Dans certaines régions elle avale aussi des charognes et de la chair illicite chez les Berbères comme celle des ânes.

Elle habite souvent dans les bois, les cavernes ou des lieux souvent considérés comme hantés. Deux choses sont capables de la dissuader de s'attaquer aux hommes, particulièrement aux enfants: l'eau et l'allaitement. En effet, dans les poursuites d'enfants, c'est souvent l'eau d'un ruisseau ou d'un simple ru qui l'arrête. L'enfant peut aussi se sauver en se jetant, par surprise, sur une mamelle de l'ogresse et la téter. Cet acte scelle une alliance où l'ogresse va se consacrer à aider l'enfant.

4 On le voit, ces deux portraits montrent que le personnage le plus consistant est l'ogresse. En-dehors de sa brutalité et sa violence, l'ogre est un pâle personnage. On le 
voit d'ailleurs mieux lorsque le conte met en scène un couple ogre-ogresse. Cette dernière détient le pouvoir d'agir et oriente l'action de son compère.

Les contes où apparaissent l'ogre et l'ogresse ont une caractéristique fondamentale : il thématise un drame, la mort d'un membre du couple ayant un ou plusieurs enfants. Ce membre est toujours la mère de ces enfants. Cette dernière est immédiatement remplacée par une belle-mère. Tout conte merveilleux berbère où le début du récit commence ainsi et mettra en scène un(e) ogre(sse) ou ses substituts. On pourrait avancer qu'il s'agit d'une implication logique. Car fatalement la belle-mère demandera au père des enfants de tuer ses enfants ou de les abandonner loin dans la forêt ou le désert pour qu'ils s'y perdent. C'est là qu'ils rencontrent l'ogre et/ou l'ogresse. Cette structure est fondamentale puisqu'elle se retrouve dans tous les contes merveilleux où un père ayant perdu sa femme en épouse une autre pour qu'elle s'occupe des enfants de son mari.

Quand cette femme a des enfants avec cet homme, elle éloigne les demi-frères et demisœurs pour l'intérêt exclusif des siens ; quand elle n'en a pas, plusieurs alibis sont mis scène comme la jalousie à cause de sa beauté de la belle-fille ou de la connivence des enfants avec leur père, etc.

7 On dira alors que l'ogre/l'ogresse apparaît lorsqu'il y a un désordre familial ou social, lorsqu'il est question de dissoudre les liens familiaux, lorsque la situation devient manichéenne : la vie ou la mort.

8 On sait que ce nœud du conte merveilleux berbère a suscité de nombreuses interprétations qui, ramenées à des disciplines, sont essentiellement ethnographiques, anthropologiques et sémiologiques, Depuis quelques années on assiste à l'intérêt de la psychanalyse pour ces contes.

9 Certes, l'ethnologie et l'anthropologie y cherchent les constituants de la 'mentalité' berbère ou, pour parler comme Bourdieu, une théorie de la pratique; la sémiotique $\mathrm{y}$ cherche généralement la validation d'une grammaire narrative universelle et subsidiairement une grammaire spécifique.

10 La psychanalyse, quant à elle, commence par y chercher la spécificité de l'œdipe berbère avant d'élargir sa curiosité à des mécanismes plus généraux comme l'imaginaire et le symbolique. Quel sens donne-t-elle à l'ogre/l'ogresse? Résumons la position de N. Farès (1994) :

1. Le nœud du conte est interprété comme situation œdipienne marquée par l'interdit de l'inceste. En effet, dans un conte où se manifeste la jalousie d'un fils à l'égard de son père et/ ou de sa belle mère, il y a crise œdipienne.

2. L'ogre et l'ogresse représentent, au plan de l'imaginaire, le mauvais père/la mauvaise mère qui vont aider l'enfant à traverser cette crise et sortir ainsi de l'œdipe.

11 En d'autres termes, l'ogre et l'ogresse représentent des fonctions psychiques, le côté noir des relations familiales. 


\section{BIBLIOGRAPHIE}

BASSET H., Essai sur la littérature des Berbères, Alger, Carbonel, 1920.

BASSET R., Les contes populaires berbères, Paris, Leroux, 1887.

BOUNFOUR A., « Hemmu u Namir ou l'ÆEdipe berbère », Etudes et documents berbères, 14, 1996,

p. $119-142$.

DOUTTÉ E., Magie et religion dans l'Afrique du Nord, Alger, Jourdan, 1909.

FARES N., L'ogresse dans la littérature orale berbère, Paris, Karthala, 1994.

LACOSTE-DUJARDIN C., Le conte kabyle, Paris, Maspero, 1970.

LAOUST E., Contes berbères du Maroc, 2 tomes, Paris, Larose, 1949.

ORTIGUES E. et M.-C., EEdipe africain, Paris, Plon, 1950.

ROUX A., Poésies populaires berbères, présentation, transcription, traduction et annotations de A.

Bounfour, Paris/Aix-en-Provence, Editions du CNRS (LAPMO), 1990.

\section{NOTES}

1. Que Laoust interprète, certainement à tort, en « mangeur d'ânes » $(1949, \mathrm{II}, \mathrm{p} . \mathrm{XX})$; il faut, plus

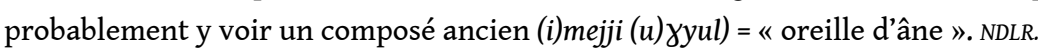

2. Notons que l'ogresse kabyle peut prendre l'apparence d'une belle femme. NDLR.

INDEX

Mots-clés : Ethnologie, Littérature, Maroc 